\title{
Zanggers Seminar
}

E. Taverna

Vielleicht sollte ich für längere Zeit ausspannen, denkt Zangger auf der ersten Buchseite. Es ist Frühling und die Patienten gehen ihm auf die Nerven. Dann fegt der Wind die letzten Blätter von den Bäumen, es riecht nach Schnee und die Erzählung endet mit dem gleichen Vorsatz. Dazwischen wird ein Jahr vergehen, das seinen Alltagstrott gründlich durcheinander bringt. Selten wurde ein Berufscurriculum so spannend erzählt. Denn was sich in Zanggers Seminarräumen im Zürcher «Götterquartier» zuträgt, zieht den Leser in ein Schicksal hinein, das unaufhaltsam die Biographien der Schüler mit der Vergangenheit des Lehrers verknüpft. Dem Autor Kaspar Wolfensberger gelingt das Kunststück, seine eigenen Berufserfahrungen zu einem filmreifen Bühnenstück umzuschreiben. Eine junge Frau verwirrt den erfahrenen Dozenten und sein Burnout ist wie weggeblasen. Er nennt sie Blumenmädchen, entdeckt in ihr die blonde blumenstreuende Flora Botticellis, das Lächeln früherer Geliebten, ist hingerissen und eifersüchtig. Zum Glück hat er seinen professionellen Verstand und seinen alten Schulfreund und Supervisor Seidelbast. Dieser versteht etwas von Büchern und Wein und hält wie Zangger nicht viel von Theorien. In flüssigen Dialogen inszeniert der Autor ein Psychodrama, in dem Leser und Leserinnen ganz unaufdringlich eine professionelle Einführung in die Techniken einer psychiatrischen Ausbildung erhalten. Zangger arbeitet im Hottinger Stadtviertel, wo viele Psychiater, Therapeuten und Analytiker wie er selber in schönen Reihenhäusern mit Vorgärtchen ihre Klienten empfangen. Als ein Praktiker, der seinen Kandidaten eine «reich bestückte Werkzeugkiste» mitgeben will, ist der Kenner der Szene kein Freund orthodoxer, artreiner Schulen. Während er seine Gedanken zu einem Seminar über Angstprobleme ordnet, lässt er das aktuelle Psychospektrum Revue passieren: «Immer nur Träume deuten, unabhängig davon, woran der Patient litt? In der Vergangenheit graben, die Beziehung zum Vater, zur Mutter erforschen, ganz gleich, was einen plagte? Unbefriedigte Bedürfnisse aufdecken, was immer das Problem war? Nach unbewussten Konflikten fahnden, egal, was einem fehlte? Stets die Aussagen des Patienten und seine Befindlichkeit spiegeln? Immer Interaktionsmuster analysieren und Lebenspläne aufdecken? Beharrlich

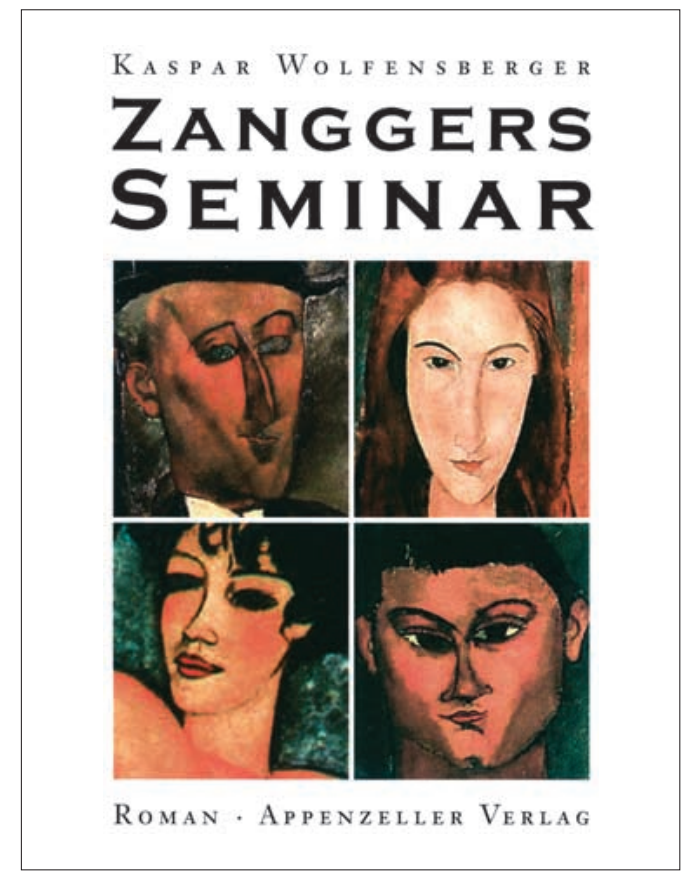

im Hier und Jetzt bleiben, sich selber nachspüren, stereotyp zum leeren Stuhl reden? Den Muskelpanzer aufweichen, aufs Kissen schlagen, unterdrückte Gefühle herausschreien, in jedem einzelnen Fall? Ausschliesslich Gedankengänge korrigieren? Verhaltenstraining so oder so? Jeden zurückführen in die Kindheit oder noch weiter zurück? Familienaufstellung als Schlüssel zum Heil? Immer bloss «Mhm〉 sagen oder «Erzählen Sie mehr〉 oder 〈Was kommt Ihnen dazu in den Sinn?> - Wie im Mittelalter: immer zur Ader lassen, ganz gleich unter welcher Krankheit einer litt? Nein!»

Doch selbst der Erfahrene und mit allen Wassern Gewaschene sitzt letztlich einer Täuschung auf. Die Verdoppelung der Waldläufe, das neue Krafttraining, die schicken Hemden und das andere Rasierwasser machen die Ehefrau misstrauisch. Und Zangger? Das Ende kommt überraschend und unerwartet. Fast tut es einem leid, dass die Geschichte zu Ende geht. Ein Abschied, der vielleicht dazu einlädt, sich noch andere Schlussvarianten auszudenken. Um mit den Figuren noch weiterzuleben? Das wäre schon ein weiteres Seminarthema oder der nächste Roman.

Kaspar Wolfensberger. Zanggers Seminar. Herisau: Appenzeller Verlag; 2002. 274 Seiten. 